\title{
Effects of Combined Spinal Epidural Anaesthesia and Spinal Anaesthesia on Peri-Operative Pulmonary Status in Geriatric Patients in Lower Extremity Surgery
}

\author{
Sharmin Ara Begum 1* A. K. M. Akhtaruzzaman², Dilip Kumar Bhowmick², Debabrata Banik², \\ Md. Afzalur Rahman'3 , A. K. M. Shahidur Rahman', Md. Saydur Rahman", \\ Khandoker Moynul Hasan6, Mohammad Kamrul Ahsan7, Md. Imrul Islam, \\ Muhammad Shamsul Arefin ${ }^{3}$, Tahmidul Islam9
}

\footnotetext{
${ }^{1}$ Department of Anaesthesiology, National Institute of Traumatology and Orthopedic Rehabilitation (NITOR), Dhaka, Bangladesh ${ }^{2}$ Department of Anaesthesia, Analgesia and Intensive Care Medicine, Bangabandhu Sheikh Mujib Medical University (BSMMU), Dhaka, Bangladesh

${ }^{3}$ Department of Neuro-Anaesthesia, National Institute of Neurosciences and Hospital (NINS), Sher-e-Bangla Nagar, Agargaon, Dhaka, Bangladesh

${ }^{4}$ Department of Nephrology, Bangabandhu Sheikh Mujib Medical University (BSMMU), Dhaka, Bangladesh

${ }^{5}$ Department of Anaesthesia, Asgor Ali Hospital, Dhaka, Bangladesh

${ }^{6}$ Department of Pediatric Surgery, Shaheed Suhrawardy Medical College and Hospital, Dhaka, Bangladesh

${ }^{7}$ Holy Family Red Crescent Medical College Hospital (HFRCMCH), Dhaka, Bangladesh

${ }^{8}$ Department of Anaesthesiology and Intensive Care Unit (ICU), Rajshahi Medical College Hospital (RMCH), Rajshahi, Bangladesh

${ }^{9}$ Department of Biochemistry, Bangabandhu Sheikh Mujib Medical University (BSMMU), Dhaka, Bangladesh

Email: *sharminbilkis1975@gmail.com
}

How to cite this paper: Begum, S.A., Akhtaruzzaman, A.K.M., Bhowmick, D.K., Banik, D., Rahman, Md.A., Rahman, A.K.M.S., Rahman, Md.S., Hasan, K.M., Ahsan, M.K., Islam, Md.I., Arefin, M.S. and Islam, T. (2020) Effects of Combined Spinal Epidural Anaesthesia and Spinal Anaesthesia on Peri-Operative Pulmonary Status in Geriatric Patients in Lower Extremity Surgery. Journal of Biosciences and Medicines, 8, 132-147. https://doi.org/10.4236/jbm.2020.810012

Received: September 22, 2020

Accepted: October 19, 2020

Published: October 22, 2020

\begin{abstract}
Background: Lower extremity surgeries performed in elderly people usually have high prevalence of peri-operative medical problems related to anaesthesia. The overall objective of peri-operative care of geriatric population is to fast recovery from anaesthesia and avoid functional decline. Objective: To compare the peri-operative pulmonary status of combined spinal epidural anaesthesia (CSEA) and spinal anaesthesia (SA) in geriatric patients underwent lower extremity surgeries. Methods: This prospective comparative study was conducted at Department of Anaesthesia, Analgesia and Intensive Care Medicine, Bangabandhu Sheikh Mujib Medical University (BSMMU), Dhaka, Bangladesh from July 2016 to June 2018. A total of 70 geriatric cases that underwent lower extremity surgeries were included in this study. Cases were randomly allocated into two groups; 35 in Group A (CSEA) and 35 in Group $\mathrm{B}(\mathrm{SAB})$. The different outcome variables between the groups like-duration of anaesthesia, respiratory rates (RR), oxygen saturation $\left(\mathrm{SpO}_{2}\right)$, end tidal $\mathrm{CO}_{2}$
\end{abstract}


Copyright $\odot 2020$ by author(s) and Scientific Research Publishing Inc. This work is licensed under the Creative Commons Attribution International License (CC BY 4.0).

http://creativecommons.org/licenses/by/4.0/ (c) (i) Open Access
$\left(\mathrm{EtCO}_{2}\right)$, peak expiratory flow rate (PEFR), breath holding test (BHT), peri-operative side effects of anaesthesia and post-operative visual analogue score (VAS) were analyzed and compared by statistical tests. Results: The mean age, weight, BMI of Group A and Group B patients were not significantly different $(p>0.05)$. No significant differences were observed in duration of surgery, gender and ASA grade between the groups $(p>0.05)$. Mean duration of anaesthesia, mean time to achieve target level of sensory block and mean time to achieve complete motor block were significantly higher in Group A $(p<0.001)$. Mean RR, $\mathrm{SpO}_{2}, \mathrm{EtCO}_{2}, \mathrm{PEFR}$ and BHT of both groups were not significantly different $(p>0.05)$. Peri-operative side effects of anaesthesia and post-operative VAS were significantly less in group A patients $(p<0.05)$. Conclusion: Combined spinal epidural anaesthesia is effective and safe; produces stable peri-operative pulmonary status with prolonging analgesia and fewer side effects as compared to spinal anaesthesia in geriatric patients.

\section{Keywords}

Combined Spinal Epidural Anaesthesia (CSEA), Geriatric Patients, Spinal Anaesthesia (SA)

\section{Introduction}

Aging is a progressive physiological phenomenon characterized by degenerative changes in both structural and functional capacity of organs and tissues. Geriatric arbitrarily refers to patients of more than 65 years old [1]. Cardiovascular, nervous, pulmonary, endocrine, and immune systems can all be affected by human aging processes [2]. These patients are more sensitive to anaesthetic agents and less amount of anaesthetic medication is usually required to achieve the desired clinical effects [1] [2]. It was reported that geriatric patients undergoing major surgery have a significantly higher incidence of morbidity and mortality compared with the younger age group because of their reduced cardio-respiratory reserve [3].

Changes in the respiratory system with age comprise decline in compliance of bony thorax, loss of respiratory muscle mass, decrease in alveolar gas exchange surface and decrease in central system responsiveness [1]. Alterations of pulmonary variables in healthy and even in elderly patients during neuraxial block are usually of little clinical consequences [4]. Blockade of the intercostal and abdominal muscles during neuraxial anaesthesia is adequately compensated by unaltered function of the diaphragm and other accessory respiratory muscles especially for forceful inspiration and expiration [4]. High thoracic block leaves tidal volume unchanged and there is only a slight decrease in vital capacity from loosing abdominal muscles [4]. However, coexisting morbidities should be carefully considered when choosing neuraxial blockade in elderly patients [3] [4]. Neuraxial blockade of intercostal and abdominal muscles may have a negative 
impact on the ability which relies on these muscles for respiration and clearing of secretion [4]. Moreover, neuraxial block can reduce the odds of pulmonary embolism by $55 \%$ and deep vein thrombosis by $44 \%$ [5].

It was reported that simultaneous administration of different anaesthetic techniques on the same patient improves effectiveness and reduces side effects [6]. Spinal anaesthesia (SA) provides fast and reliable segmental anaesthesia with minimal risk for toxicity [6] [7]. Spinal anaesthesia is contraindicated when the operation is expected to take longer than the duration of the block or result in blood loss such that the development of severe hypovolemia is likely, while epidural anaesthesia provides peri-operative anaesthesia (alone or in combination with general anaesthesia), followed by excellent analgesia in the post-operative period [7]. On the other hand, combined spinal epidural anaesthesia (CSEA) reduces the potential problems, such as the somewhat unpredictable level of blockade after spinal anaesthesia, and the problems of missed segments, incomplete motor block, poor sacral spread and local anaesthetic toxicity that can occur with epidural anaesthesia [7]. Major benefits of CSEA are low doses of medications, low incidence of motor blockade, adequate sensory block and the ability to extend the area of blockade [7] [8]. However, use of CSEA also introduces few potential complications, such as technical failure, altered spread of epidural drugs in patients who also had a lumbar puncture and altered spread of subarachnoid medications due to the effects of the epidural injection [8].

The block in CSEA resulted from a relatively small amount of the local anaesthetic through spinal route followed by epidural drug which helps to increase the subarachnoid block to desired level for caesarean section [9]. Many considerations have been given as to how epidural top up works after a spinal anaesthesia in combined spinal epidural anaesthesia [9] [10] [11].

The sequential combined spinal epidural anaesthesia is now being used in elderly high risk patients for orthopedic surgery with encouraging results [12]. The onset of block is not delayed by this method but at the same time adequate level of sensory block is obtained [12] [13]. The block is then deliberately extended cephaled with the epidural drug [13]. It has been reported that the sequential combined spinal epidural anaesthesia is particularly advantageous in high risk old orthopedic patients where gentle onset of sympathetic block is desirable to reduce haemodynamic side effects [12] [14].

Combined spinal epidural anaesthesia is now widely used in urologic, obstetrics, orthopedic, abdominal, vascular and gynecologic surgeries [15] [16] [17]. Combined spinal epidural anaesthesia allows the use of very low subarachnoid drug doses, due to the synergistic interaction between subarachnoid and epidural drugs [15]. The CSEA is very appropriate for outpatient surgery, because the block wears off rapidly, so that patients ambulate earlier and can be discharged home sooner [18].

There is scarce evidence that compares the pulmonary effects of combined spinal-epidural anaesthesia versus spinal anaesthesia in geriatric patients. Therefore this study was done to compare the peri-operative pulmonary effects of 
combined spinal-epidural anaesthesia and spinal anaesthesia in geriatric patients underwent lower extremity surgery.

\section{Methodology}

This prospective randomized comparative study was conducted at the Department of Anaesthesia, Analgesia and Intensive Care Medicine, Bangabandhu Sheikh Mujib Medical University (BSMMU), Dhaka, Bangladesh during the period of July 2016 to June 2018. This study was approved by the Ethical Review Committee, BSMMU, Dhaka, Bangladesh. A total of seventy (70) patients were selected as cases by statistical calculation. Informed written consent was taken from each study subject prior to enrollment. Physical status of the patients was assessed by American Society of Anaesthesiologist (ASA) scoring system [19]. The study subjects were selected according to the selection criteria. Patients of both sexes, age more than 65 years, selected for lower extremity surgical procedures [like-hemi arthroplasty, knee replacement surgery, dynamic hip screw (DHS), ORIF of shaft of femur fracture, proximal femoral nail (PFN), ORIF of tibia-fibula fracture, repair of tendo-achilles etc.] and patients having ASA grade (Physical status) I, II \& III were included in this study. Patients with the absolute contraindication for regional anaesthesia, obese patients $\left(B M I \geq 30 \mathrm{~kg} / \mathrm{m}^{2}\right)$, alcohol/drug abuser and patients with neurological, psychiatric or neuromuscular disorder were excluded from the study. In this study, peri-operative period refers to the period just before (before induction of anaesthesia), during and after (24 hours) surgery. The patients were randomly allocated into two equal groups (group A and group B); 35 patients were in Group A and 35 patients were in Group B. Patients of group A were received CSEA by using 27G Quincke spinal needle through needle technique and patients of group $B$ were received subarachnoid block (SAB) by using 25G spinocaine needle. During the peri-operative period all patients had standard monitoring like-electrocardiogram (ECG), noninvasive blood pressure (NIBP), pulse oximetry and side stream capnography.

\subsection{Sample Size Estimation}

The approximate sample size formula for binary outcomes, assuming $\alpha=0.05$ power $=0.80$ and equal sample size in the two groups.

$n=$ the sample size in each of the groups.

$P_{1}=$ event rate in the treatment group (Combined spinal-epidural anaesthesia) (when $R$ and $P_{2}$ are estimated).

$P_{2}=$ event rate in the control group (spinal anaesthesia).

$R$ risk ratio $\left(P_{1} / P_{2}\right)$

To determine the sample size, the following formula was used;

$$
n=\frac{7.85\left[(R+1)-p_{2}\left(R^{2}+1\right)\right]}{p_{2}(1-R)^{2}}
$$

Estimate a $66.67 \%$ in the control group (spinal anaesthesia) $\left(P_{2}=0.6667\right)$ and 
determine that the clinically important difference to detect a $50.0 \%$ reduction ( $R$ $=2.02$ ) with the treatment group (CSEA) at $\alpha=0.05$ and power $=0.80$ [20].

(Note: $R=2.02$ equates to an event rate in the treatment group of $P_{1}=0.33$, i.e.,

$$
\begin{aligned}
& R=33 \% /(66.67 \%) \\
& P_{1}=0.33 \\
& P_{2}=0.6667 \\
& R=2.02
\end{aligned}
$$

$$
n=\frac{7.85\left[(2.02+1)-0.6667\left(2.02^{2}+1\right)\right]}{0.6667(1-2.02)^{2}}
$$

$n=30.6=31$ in each group (group A = CSEA and group B = Spinal anaesthesia).

Additional 4 cases were included in each group. Therefore total $35 \times 2=70$ cases were enrolled in this study.

\subsection{Procedure}

Intravenous line with $18 \mathrm{G} \mathrm{I/V} \mathrm{cannula} \mathrm{was} \mathrm{secured} \mathrm{and} \mathrm{a} \mathrm{preload} \mathrm{of} 500 \mathrm{ml}$ Ringer's lactate solution was given to every patient before giving regional anaesthesia. The patients were supported in sitting posture on a horizontal table, by an assistant. The lumber area was prepared aseptically and draped.

The intervertebral space at $\mathrm{L}_{2-3}$ and $\mathrm{L}_{3-4}$ was identified. The prick point infiltrated with $2 \mathrm{ml}$ of $1 \%$ lignocaine. Identification of epidural space was done by using loss of resistance technique. Patients of Group A $(n=35)$ were received sequential combined spinal epidural anaesthesia with $1 \mathrm{ml}(5 \mathrm{mg})$ of $0.5 \%$ hyperbaric bupivacaine and 25 microgram fentanyl through $27 \mathrm{G}$ Quincke spinal needle which was introduced through a $18 \mathrm{G}$ Tuohy needle in the epidural space. The dose of spinal hyperbaric bupivacaine was intentionally kept small because the aim to produce a block restricted to $\mathrm{T}_{10}$ spinal segment. The spinal needle was withdrawn after injection of drug into subarachnoid space and a $20 \mathrm{G}$ epidural catheter was inserted and secured. In Group A, $1.0-1.5 \mathrm{ml}$ of $0.5 \%$ isobaric bupivacaine was given for every unblocked segment through epidural route to extend the block to $T_{10}$. Then the patient was placed in supine position.

Patients of Group B $(n=35)$ were received spinal anaesthesia with $2.5 \mathrm{ml}$ $(12.5 \mathrm{mg})$ of $0.5 \%$ hyperbaric bupivacaine and 25 microgram fentanyl through 25G Quincke babcock spinal needle in sitting position. Then they kept supine for gradual onset of block.

Sensory changes was recorded bilaterally after 3 minutes by assessing changes in pin prick sensation [graded according to Gormley and Hill (Normal sensation $=0$, blunted sensation $=1$, no sensation $=2$ )] [20].

The degree of motor block of lower limbs was assessed bilaterally using Bromage Scale $(1=$ no motor block, 2 = can flex knee, move foot, but cannot raise 
leg, 3 = can move foot only, $4=$ cannot move foot or knee) [20].

\subsection{Outcome Variables}

The following variables were monitored and recorded in peri-operative period (before induction of anaesthesia, throughout the surgical procedure and at post-operative ward):

- Onset and level of sensory block.

- Degree of motor block.

- Duration of anaesthesia.

- Respiratory variables such as-respiratory rate (RR), oxygen saturation $\left(\mathrm{SpO}_{2}\right)$, end-tidal $\mathrm{C}_{\mathrm{O} 2}\left(\mathrm{EtC}_{\mathrm{O} 2}\right)$, peak expiratory flow rate (PEFR), breath holding test (BHT) were monitored at pre-operative period, at 15 minutes after block and at 15 minutes after patient arrival at post-operative ward. But respiratory rate (RR) and oxygen saturation $\left(\mathrm{SpO}_{2}\right)$ were monitored pre-operatively and at every 15 minutes, 30 minutes, 60 minutes, 90 minutes, 120 minutes time interval both in intra-operative and post-operative periods. Every episode of $\mathrm{SpO}_{2}$ below $90 \%$ was noted. Respiratory depression was defined as $\mathrm{RR}<10 / \mathrm{min}$ or $\mathrm{SpO}_{2}<85 \%[21]$.

- Intra-operative side effects to anaesthesia among the study patients (such as-nausea, vomiting, shivering, hypotension etc.) were recorded accordingly.

- Patients in group A were received $5 \mathrm{ml}$ of $0.125 \%$ isobaric bupivacaine through the epidural catheter at every 4 hours interval and patients of group $B$ received parenteral opioids (inj. pethidine $1 \mathrm{mg} / \mathrm{kg} 6$ hourly I/M on demand). Post-operative analgesia was assessed by visual analogue scale (VAS) at $1,2,6,12$ and 24 hours.

\subsection{Statistical Analysis of Data}

All the collected data were compiled on a master data chart first. Then data were organized by scientific calculator using standard statistical formula. Statistical analysis was performed using the statistical package for social sciences (SPSS) version 22.0 for windows (SPSS INC., Chicago, Illinois, USA). Categorical data were presented as frequency/percentage and continuous variable was expressed as mean $\pm \mathrm{SD}$ (standard deviation). The statistics used to analyze the data were descriptive statistics and the tests done were Student's "t" test and Chi-square test. The level of significance was set at 0.05 and $p$ value $<0.05$ was considered significant.

\section{Results and Observations}

This prospective study was conducted to compare the peri-operative pulmonary status of CSEA and spinal anaesthesia (SA) in geriatric patient underwent lower extremity surgery. Total seventy (70) patients were randomly allocated into two groups: group A and group B; 35 in each group, where patients in group A were received CSEA and patients in group $B$ were received SAB. 
The mean $( \pm \mathrm{SD})$ age of group A patients was $69.29 \pm 5.39$ years and that was $70.23 \pm 6.6$ years in group B patients $(p=0.516)$. Mean $( \pm S D)$ weight $(\mathrm{kg})$ and BMI $\left(\mathrm{kg} / \mathrm{m}^{2}\right)$ were $55.37 \pm 7.5 \mathrm{~kg}, 58.06 \pm 7.81 \mathrm{~kg}$ and $22.86 \pm 3.95 \mathrm{~kg} / \mathrm{m}^{2}, 23.73$ $\pm 4.91 \mathrm{~kg} / \mathrm{m}^{2}$ in group A and group B respectively ( $p=0.146$ and $p=0.417$ respectively). There were no statistically significant differences were observed in duration of surgery, gender and ASA grade between the groups ( $p=0.480, p=$ 0.809 and $p=0.557$ respectively) (Table 1 ).

It was observed that, the mean $( \pm \mathrm{SD})$ duration of anaesthesia was significantly higher in Group A than Group B (256.57 \pm 33.56 minutes versus $214.71 \pm 18.03$ minutes, $p<0.001)$. Mean $( \pm \mathrm{SD})$ time to achieve target level of sensory block was significantly higher in Group A than Group B (11.21 \pm 2.2 minutes versus $3.5 \pm 1.5$ minutes, $p<0.001)$. Mean $( \pm \mathrm{SD})$ time to achieve complete motor block was also significantly higher in Group A than Group B (12.29 \pm 2.53 minutes versus $7.02 \pm 2.11$ minutes, $p<0.001$ ) (Table 2 ).

The mean respiratory rates (RR-per minutes) of both groups were maintained within normal range throughout the peri-operative period. Mean respiratory rate of both groups at pre-operative, different intra-operative and post-operative periods were not significantly different $(p>0.05)$ (Table 3$)$.

Table 1. Demographic characteristics of the study population $(N=70)$.

\begin{tabular}{|c|c|c|c|}
\hline Particulars of the patient & $\begin{array}{c}\text { Group-A } \\
n=35\end{array}$ & $\begin{array}{c}\text { Group-B } \\
n=35\end{array}$ & $p$ value \\
\hline Age (in years) & $69.29 \pm 5.39$ & $70.23 \pm 6.6$ & ${ }^{\star} 0.516^{\mathrm{ns}}$ \\
\hline Weight (kg) & $55.37 \pm 7.5$ & $58.06 \pm 7.81$ & ${ }^{\star} 0.146^{\mathrm{ns}}$ \\
\hline BMI $\left(\mathrm{kg} / \mathrm{m}^{2}\right)$ & $22.86 \pm 3.95$ & $23.73 \pm 4.91$ & ${ }^{\star} 0.417^{\mathrm{ns}}$ \\
\hline Duration of surgery (minutes) & $123.43 \pm 24.9$ & $116.43 \pm 27.83$ & ${ }^{\star} 0.275^{\mathrm{ns}}$ \\
\hline \multicolumn{4}{|l|}{ Gender [n (\%)] } \\
\hline Male & $16(45.7)$ & $15(42.9)$ & \multirow{2}{*}{${ }^{* *} 0.809^{\text {ns }}$} \\
\hline Female & $19(54.3)$ & $20(57.1)$ & \\
\hline \multicolumn{4}{|l|}{ ASA Grade [n (\%)] } \\
\hline Grade 1 & $6(17.1)$ & $3(8.6)$ & \\
\hline Grade 2 & $25(71.4)$ & $28(80.0)$ & ${ }^{* *} 0.557^{\mathrm{ns}}$ \\
\hline Grade 3 & $4(11.4)$ & $4(11.4)$ & \\
\hline
\end{tabular}

Values are expressed as mean \pm SD. Values within parenthesis denotes corresponding percentages. ASA = American Society of Anaesthesiologist, $\mathrm{ns}=$ not significant, ${ }^{*} p$ value reached from unpaired student's t-test, ${ }^{* *} p$ value reached from Chi square test.

Table 2. Central neuraxial block assessment of the study patients $(N=70)$.

\begin{tabular}{cccc} 
Parameters & Group-A \\
$\boldsymbol{n}=35$ & $\begin{array}{c}\text { Group-B } \\
\boldsymbol{n}=35\end{array}$ & $\boldsymbol{p}$ value \\
\hline Duration of Anaesthesia (minutes) & $256.6 \pm 33.6$ & $214.7 \pm 18.0$ & $0.001^{\mathrm{s}}$ \\
Time to achieve sensory block at $\mathrm{T}_{10}$ level (minutes) & $11.2 \pm 2.2$ & $3.5 \pm 1.5$ & $0.001^{\mathrm{s}}$ \\
Time to achieve complete motor block (minutes) & $12.3 \pm 2.5$ & $7.02 \pm 2.1$ & $0.001^{\mathrm{s}}$ \\
\hline
\end{tabular}

Values are expressed as mean \pm SD. $s$ = significant, $p$ value calculated by unpaired student's t-test. 
Table 3. Respiratory rate (RR) of the study patients at different time intervals.

\begin{tabular}{cccc}
\hline Respiratory rate (per minutes) & $\begin{array}{c}\text { Group-A } \\
\boldsymbol{n}=35\end{array}$ & $\begin{array}{c}\text { Group-B } \\
\boldsymbol{n}=35\end{array}$ & $\boldsymbol{p}$ value \\
\hline Pre-operative & $16.94 \pm 0.76$ & $17.27 \pm 1.01$ & $0.127^{\text {ns }}$ \\
Intra-operative & & & \\
15 min after induction & $16.77 \pm 0.91$ & $17.49 \pm 1.12$ & $0.083^{\text {ns }}$ \\
After 30 minutes & $16.20 \pm 1.11$ & $16.57 \pm 0.82$ & $0.117^{\text {ns }}$ \\
After 60 minutes & $16.00 \pm 0.97$ & $16.41 \pm 0.74$ & $0.051^{\text {ns }}$ \\
After 90 minutes & $16.32 \pm 0.91$ & $16.64 \pm 0.82$ & $0.127^{\text {ns }}$ \\
After 120 minutes & $16.44 \pm 1.02$ & $16.51 \pm 0.61$ & $0.729^{\text {ns }}$ \\
Post-operative & & & \\
15 min after at arrival at post-operative ward & $16.54 \pm 0.98$ & $16.91 \pm 0.82$ & $0.091^{\text {ns }}$ \\
After 30 minutes & $16.4 \pm 1.09$ & $16.8 \pm 0.68$ & $0.698^{\text {ns }}$ \\
After 60 minutes & $16.4 \pm 0.88$ & $16.86 \pm 0.85$ & $0.073^{\text {ns }}$ \\
After 90 minutes & $16.34 \pm 0.87$ & $16.74 \pm 0.78$ & $0.089^{\text {ns }}$ \\
After 120 minutes & $16.57 \pm 0.65$ & $16.34 \pm 0.54$ & $0.112^{\text {ns }}$ \\
\hline
\end{tabular}

Values are expressed as mean $\pm \mathrm{SD}$. ns = not significant, $p$ value reached from unpaired student's t-test.

The pre-operative oxygen saturation $\left(\mathrm{SpO}_{2}-\%\right)$ was almost similar in both groups $(p=0.058)$. The mean $\mathrm{SpO}_{2}$ of both groups were maintained within normal range throughout the intra-operative period that was not significantly different $(p>0.05)$. The mean $\mathrm{SpO}_{2}$ of both groups at different post-operative follow up periods were also within normal range and were not significantly different $(p>0.05)$ (Table 4).

The mean End tidal $\mathrm{CO}_{2}\left(\mathrm{EtCO}_{2}-\mathrm{mm}\right.$ of $\left.\mathrm{Hg}\right)$ of both groups were not significantly different at pre-operative period, 15 minutes after induction of anaesthesia and 15 minutes after arrival of patients in post-operative ward $(p>0.05)$ (Table 5).

The Peak Expiratory Flow Rate (PEFR-per minute) of both groups were not significantly different at pre-operative period, 15 minutes after induction of anaesthesia and 15 minutes after arrival of patients in post-operative ward ( $p>$ 0.05) (Table 6).

The breath holding test (BHT) of both groups were not significantly different at pre-operative period, 15 minutes after induction of anaesthesia and $15 \mathrm{mi}$ nutes after arrival of patients in post-operative ward $(p>0.05)$ (Table 7).

Table 8 shows intra-operative side effects of anaesthetsia among the study patients, it was observed that almost one third patients had developed shivering in group A [12 (34.3\%)] and group B [11 (31.4\%)]. While, 6 (17.1\%) patients developed hypotension in group A which was $16(45.7 \%)$ patients in group B, nausea occurred among $6(17.1 \%)$ patients in group A and 1 (2.9\%) patient in group B. On the other hand only 1 (2.9\%) patient vomited in group B in the intra-operative period. Intra-operative side effects of anaesthetsia were not observed 
Table 4. Oxygen saturation $\left(\mathrm{SpO}_{2}\right)$ of the study patients at different time intervals.

\begin{tabular}{cccc}
\hline $\mathrm{SpO}_{2}(\%)$ & $\begin{array}{c}\text { Group-A } \\
\boldsymbol{n}=35\end{array}$ & $\begin{array}{c}\text { Group-B } \\
\boldsymbol{n}=35\end{array}$ & $\boldsymbol{p}$ value \\
\hline Pre-operative & $99.54 \pm 0.56$ & $99.77 \pm 0.43$ & $0.058^{\text {ns }}$ \\
Intra-operative & & & \\
15 minutes after induction & $99.23 \pm 0.69$ & $99.46 \pm 0.61$ & $0.144^{\text {ns }}$ \\
After 30 minutes & $98.80 \pm 0.90$ & $99.20 \pm 0.8$ & $0.054^{\text {ns }}$ \\
After 60 minutes & $98.94 \pm 0.97$ & $99.03 \pm 0.75$ & $0.773^{\text {ns }}$ \\
After 90 minutes & $98.97 \pm 0.75$ & $99.14 \pm 0.69$ & $0.353^{\text {ns }}$ \\
After 120 minutes & $99.06 \pm 0.84$ & $99.04 \pm 0.77$ & $0.082^{\text {ns }}$ \\
Post-operative & & & \\
15 minutes after arrival at post-operative ward & $98.94 \pm 0.8$ & $99.14 \pm 0.81$ & $0.302^{\text {ns }}$ \\
After 30 minutes & $98.71 \pm 0.99$ & $99.10 \pm 0.84$ & $0.080^{\text {ns }}$ \\
After 60 minutes & $99.09 \pm 0.85$ & $99.14 \pm 0.73$ & $0.793^{\text {ns }}$ \\
After 90 minutes & $99.06 \pm 0.94$ & $99.19 \pm 0.61$ & $0.062^{\text {ns }}$ \\
After 120 minutes & $99.37 \pm 0.6$ & $99.34 \pm 0.64$ & $0.840^{\text {ns }}$ \\
\hline
\end{tabular}

$\mathrm{SpO}_{2}=$ oxygen saturation; Values are expressed as mean $\pm \mathrm{SD} ; \mathrm{ns}=$ not significant; $p$ value calculated by unpaired student's t-test.

Table 5. End tidal $\mathrm{CO}_{2}\left(\mathrm{EtCO}_{2}\right)$ of the study patients at different time intervals.

\begin{tabular}{cccc}
\hline End tidal $\mathrm{CO}_{2}(\mathrm{~mm}$ of $\mathrm{Hg})$ & $\begin{array}{c}\text { Group-A } \\
\boldsymbol{n}=35\end{array}$ & $\begin{array}{c}\text { Group-B } \\
\boldsymbol{n}=35\end{array}$ & $\boldsymbol{p}$ value \\
\hline Pre-operative & $31.77 \pm 2.39$ & $31.91 \pm 2.83$ & $0.783^{\text {ns }}$ \\
15 minutes after induction of anaesthesia & $30.69 \pm 2.08$ & $30.8 \pm 2.49$ & $0.842^{\text {ns }}$ \\
15 minutes after arrival at post-operative ward & $31.03 \pm 1.82$ & $31.09 \pm 1.62$ & $0.885^{\text {ns }}$ \\
\hline
\end{tabular}

Values are expressed as mean $\pm \mathrm{SD}$. $\mathrm{ns}=$ not significant, $p$ value calculated by unpaired student's t-test.

Table 6. Peak expiratory flow rate (PEFR) of the study patients at different time intervals.

\begin{tabular}{|c|c|c|c|}
\hline PEFR (L/min) & $\begin{array}{c}\text { Group-A } \\
n=35\end{array}$ & $\begin{array}{c}\text { Group-B } \\
n=35\end{array}$ & $p$ value \\
\hline Pre-operative & $205.43 \pm 30.62$ & $217.71 \pm 39.86$ & $0.153^{\mathrm{ns}}$ \\
\hline 15 minutes after induction & $190.29 \pm 28.33$ & $200.57 \pm 34.12$ & $0.175^{\text {ns }}$ \\
\hline 15 minutes after arrival at post-operative ward & $179.71 \pm 30.24$ & $180.86 \pm 37.05$ & $0.887^{\mathrm{ns}}$ \\
\hline
\end{tabular}

PEFR = Peak Expiratory Flow Rate; Values are expressed as mean $\pm \mathrm{SD}$; ns $=$ not significant, $p$ value reached from unpaired student's t-test.

Table 7. Monitoring the breath holding test (BHT) of the study patients at different time intervals.

\begin{tabular}{cccc}
\hline Breath Holding Test (seconds) & $\begin{array}{c}\text { Group-A } \\
\boldsymbol{n}=35\end{array}$ & $\begin{array}{c}\text { Group-B } \\
\boldsymbol{n}=35\end{array}$ & $\boldsymbol{p}$ value \\
\hline Pre-operative & $23.80 \pm 2.15$ & $23.51 \pm 2.58$ & $0.611^{\mathrm{ns}}$ \\
15 minutes after induction & $21.11 \pm 2.70$ & $20.80 \pm 2.44$ & $0.616^{\mathrm{ns}}$ \\
15 minutes after arrival at post-operative ward & $20.09 \pm 1.96$ & $19.91 \pm 2.28$ & $0.724^{\mathrm{ns}}$ \\
\hline
\end{tabular}

Values are expressed as mean $\pm \mathrm{SD} ; \mathrm{ns}=$ not significant; $p$ value reached from unpaired t-test. 
Table 8. Distribution of the study patients by intra-operative side effects $(N=70)$.

\begin{tabular}{cccc}
\hline Intra-operative side effects & $\begin{array}{c}\text { Group-A } \\
\boldsymbol{n}=35\end{array}$ & $\begin{array}{c}\text { Group-B } \\
\boldsymbol{n}=35\end{array}$ & $\boldsymbol{p}$ value \\
\hline Nausea & $6(17.1)$ & $1(2.9)$ & \\
Vomiting & $0(0.0)$ & $1(2.9)$ & \\
Shivering & $12(34.3)$ & $11(31.4)$ & $0.031^{\mathrm{s}}$ \\
Hypotension & $6(17.1)$ & $16(45.7)$ & \\
None & $11(31.4)$ & $6(17.1)$ & \\
\hline
\end{tabular}

Values within parenthesis denote corresponding percentages; $s$ = significant; $p$ value reached from chi square test.

among $11(31.4 \%)$ patients in group A and $6(17.1 \%)$ patients in group B. Therefore intra-operative side effects of anaesthesia were significantly less in group A patients $(p=0.031)$ (Table 8$)$.

Table 9 shows visual analog scale (VAS) score in post-operative ward of the study patients, it was observed that the mean VAS score in post-operative ward of group A varied from $1.87 \pm 1.12$ to $1.31 \pm 0.53$ and that was in group B from $5.54 \pm 1.22$ to $2.51 \pm 1.09$ during different evaluation periods. The mean VAS score in post-operative ward of group A patients remained significantly lower than that of group B patients at different follow up periods $(p<0.05)$ (Table 9).

\section{Discussion}

Aging implicates a progressive loss of functional reserve in all systems, specially cardiopulmonary [22]. A feature of this population has a high prevalence of pre-operative medical problems and often need optimization before surgery [20]. Post operative complications are more common in geriatric patients [22]. In this study our determination was to compare the peri-operative pulmonary status of combined spinal epidural anaesthesia (CSEA) and spinal anaesthesia (SA) in geriatric patients underwent lower extremity surgeries. For this reason we recruited 70 geriatric patients and randomly allocated them into two groups; 35 in group A (received CSEA) and 35 in group B (received SAB). The mean age, weight, BMI of Group A and Group B patients were not significantly different $(p>0.05)$. These findings were comparable with similar previous studies [20] [23].

The mean duration of surgery was $123.43 \pm 24.9$ minutes in group A and $116.43 \pm 27.83$ minutes in group-B $(P=0.275)$. Bhattacharya et al. (2007), in their comparative study on CSEA versus spinal anaesthesia in high risk geriatric patients for major orthopaedic surgery found mean duration of surgery was 150 \pm 10 minutes in group $A$ and $150 \pm 5.5$ minutes in group B which were higher than that of current study [23]. This difference may be due to performance of CSEA and spinal anaesthesia in major orthopaedic surgery in high risk geriatric patients and surgeon's heterogeneity.

In this current study; ASA grade I was $17.1 \%$ in group A and $8.6 \%$ in group B, 
Table 9. Distribution of the study patients by VAS score in post-operative ward $(N=70)$.

\begin{tabular}{cccc}
\hline VAS score in post-operative ward & $\begin{array}{c}\text { Group-A } \\
\boldsymbol{n}=35\end{array}$ & $\begin{array}{c}\text { Group-B } \\
\boldsymbol{n}=35\end{array}$ & $\boldsymbol{p}$ value \\
\hline After 1 hour & $1.54 \pm 0.74$ & $5.54 \pm 1.22$ & $0.001^{\mathrm{s}}$ \\
After 2 hours & $1.31 \pm 0.53$ & $2.69 \pm 0.76$ & $0.001^{\mathrm{s}}$ \\
After 6 hours & $1.87 \pm 1.12$ & $2.51 \pm 1.09$ & $0.022^{\mathrm{s}}$ \\
After 12 hours & $1.69 \pm 0.80$ & $2.80 \pm 1.18$ & $0.023^{\mathrm{s}}$ \\
After 24 hours & $1.31 \pm 0.53$ & $3.03 \pm 1.27$ & $0.001^{\mathrm{s}}$ \\
\hline
\end{tabular}

VAS = visual analog scale; Values are expressed as mean $\pm \mathrm{SD} ; \mathrm{s}=$ significant; $p$ value reached from unpaired t-test.

ASA grade II was $71.4 \%$ in group A and $80.0 \%$ in group B, and ASA grade III was $11.4 \%$ in both groups. Krishnan et al. (2018) [24] included ASA grade III, Tummala et al. (2015) [20] included ASA grade III and IV whereas Gupta et al. (2013) [25] included ASA grade I and II in their study of similar topic.

It was observed that, the mean duration of anaesthesia, mean time to achieve target level of sensory block and mean time to achieve complete motor block were significantly higher in Group A than Group B $(p<0.001)$. These findings were consistent with previous studies as reported that complete analgesia, excellent muscle relaxation, prolonged analgesia through epidural catheter was provided with sequential CSEA [20] [21] [23].

In this study the mean respiratory rate (RR) of both groups were maintained within normal range throughout the peri-operative period $(p>0.05)$. It was reported that regional anaesthesia can often reduce peri-operative pulmonary complications [2] [5]. In our study both group A and group B received $25 \mu \mathrm{g}$ fentanyl. In this dose it did not produce any respiratory depression which was dose dependent. Pusapati et al. (2010) observed no change in the respiratory rate in laparoscopic surgery under spinal anaesthesia using $15 \mathrm{mg} 0.5 \%$ bupivacaine heavy and $50 \mu \mathrm{g}$ fentanyl [26]. In that study inspiratory diaphragmatic activity under spinal anaesthesia was maintained with adequate ventilation. Our study showed similarity with this previous study.

In this present study, the patients were received CSEA and spinal block while supported in sitting posture and then they were placed in supine position. Both groups were on $4 \mathrm{~L} / \mathrm{min} \mathrm{O}_{2}$ throughout the peri-operative period by face mask. We observed that the peri-operative oxygen saturation $\left(\mathrm{SpO}_{2}\right)$ was almost similar in both groups. Our study differed from the study of Shintani et al. (2009) as showed that when the patient was positioned laterally, $\mathrm{SpO}_{2}$ decreased from $82 \%$ to $77 \%$ [27]. They reported that after introduction of local anaesthetics at sitting posture, then if patient returned to the supine position the $\mathrm{SpO}_{2}$ was immediately recovered. This decrease in $\mathrm{SpO}_{2}$ has occurred due to ventilation-perfusion mismatch. Our study was also not compatible with the study of Mutukwa et al. (2017) where their patients were premedicated with diazepam $0.1 \mathrm{mg} / \mathrm{kg}$ before introduction of spinal anaesthesia [28]. They found $16 \%$ inci- 
dence of hypoxaemia among their 50 study patients which was due to the effects of sedation. Munoz et al. (1992) also studied to determine the effects of benzodiazepine premedication on hypoxaemia during spinal anaesthesia in elderly patients and found an incidence of hypoxaemia $42 \%$ and $15 \%$ for those premedicated with midazolam and control group respectively [29]. A combination of sedation and high block predispose to a higher degree of desaturation [29]. In our study, sedative premedication was avoided and block height was maintained at $\mathrm{T}_{10}$ level by low dose of local anaesthetic in both groups.

In this current study the end tidal $\mathrm{CO}_{2}\left(\mathrm{EtCO}_{2}\right)$ in both groups were not significantly different in peri-operative period $(p>0.05)$. Pusapati et al. (2010) observed an increase in the end tidal $\mathrm{CO}_{2}$ from $31.68 \pm 4.13$ to $37.62 \pm 4.21 \mathrm{mmHg}$, reached a plateau around 15 minutes and declined after decompression of pneumoperitoneum during laparoscopic gynaecological surgery under spinal anaesthesia where the respiratory response to hypercapnia was well preserved [26]. Our study was not compatible with this previous study due to absence of pneumoperitoneum in our study population.

In this present study peak expiratory flow rates (PEFR) in both groups were not significantly different in peri-operative period $(p>0.05)$. Regli et al. (2006) showed that effective spinal anaesthesia resulted in immediate and persistent decrease in vital capacity (VC), forced vital capacity (FVC) and forced expiratory volume-1 $\left(\mathrm{FEV}_{1}\right)$ which were significantly greater in patients in obese class III than in obese class I and II [30]. The decrease in lung volumes was probably caused by abdominal muscle blockade resulting in a reduction of expiratory capacity [30]. The impact of spinal anaesthesia on PEFR was even more influential as evidenced by a reduction of more than $35 \%$ in patients with obese classes I and II and well over $45 \%$ in patients with obese class III [30]. Our study was not similar with that previous study due to exclusion of obese patients for which PEFR was well preserved in our study patients.

In this present study, peri-operative breath holding test of both groups were not significantly different $(p>0.05)$. Trembach and Zabolotskikh, (2017) showed in their study that increasing age has no effect on this pattern and the duration of breath holding time did not depend on the age [31]. Result of their study indicated a positive correlation between the duration of breath holding and vital lung capacity. The duration of voluntary apnea also depends on the lung volume [32]. Bjurstrom and Schoene (1987) showed that lung volumes has greatly influence on breath-holding [33]. On the other hand Feiner et al. (1995) identified forced vital capacity (FVC) as a significant predictor of breath hold duration [34]. The current study was not consistent with these previous studies.

In our study intra-operative side effects of anaesthesia were significantly less among group A patients compared to group B patients $(p=0.031)$. In this series similar results were observed in previous studies and documented that CSEA had much less incidence of side effects compared to spinal anaesthesia in high risk geriatric patients [14] [20] [23].

In this current study visual analog scale (VAS) score in the post-operative 
ward of group A patients remained significantly lower than that of group B patients at different post-operative follow up periods $(p<0.05)$. Swarnkar et al. (2007) observed VAS score for patient satisfaction in post-operative patients underwent total abdominal hysterectomy and reported that, VAS score was much lower in CSEA group than epidural group [35]. Our study mostly matched with this study.

This study demonstrated that there was no significant difference in peri-operative pulmonary status between combined spinal-epidural anaesthesia and spinal anaesthesia. The study showed that CSEA provide stable peri-operative pulmonary status with better post-operative analgesia and fewer incidences of side effects. It has been reported that CSEA is particularly advantageous in high risk old patients where gentle onset of sympathetic block is desirable to reduce peri-operative side effects [20] [23]. Therefore sequential CSEA is superior alternative to epidural block, which combines the advantages of spinal and epidural while minimizing their drawbacks. Further studies will be warranted to elucidate the ideal method of anaesthesia in geriatric patients.

\section{Conclusion}

Combined spinal epidural anaesthesia (CSEA) is effective and safe; produces stable peri-operative pulmonary status with provision of prolonging analgesia and fewer incidences of side effects as compared to spinal anaesthesia in geriatric patients underwent lower extremity surgery.

\section{Limitations}

It was a single centre study with a relatively small sample size.

\section{Recommendation}

A multi-center prospective study with large sample size should be done to compare the peri-operative pulmonary status of combined spinal epidural anaesthesia (CSEA) and spinal anaesthesia (SA) in geriatric patients underwent major surgeries.

\section{Conflicts of Interest}

The authors declare no conflicts of interest regarding the publication of this paper.

\section{References}

[1] Novak-Jankovič, V. (2013) Regional Anaesthesia for the Elderly Patients. Periodicum Biologorum, 115, 119-123.

[2] Nordquist, D. and Halaszynski, T.M. (2014) Perioperative Multimodal Anesthesia Using Regional Techniques in the Aging Surgical Patient. Pain Research and Treatment, 2014, Article ID: 902174. https://doi.org/10.1155/2014/902174

[3] Renck, H. (1969) The Elderly Patient after Anaesthesia and Surgery. Acta Anaesthe- 
siologica Scandinavica. Supplementum, 34, 1-136.

[4] Larson Jr., C.P. (2010) Miller's Anesthesia. Anesthesia \& Analgesia, 10, 263-265. https://doi.org/10.1213/ane.0b013e3181b7c799

[5] Rodgers, A., Walker, N., Schug, S., Mckee, A., Kehlet, H., Van Zundert, A., Sage, D., Futter, M., Saville, G., Clark, T. and Macmahon, S. (2000) Reduction of Postoperative Mortality and Morbidity with Epidural or Spinal Anaesthesia: Results from Overview of Randomised Trials. BMJ, 321, 1493. https://doi.org/10.1136/bmj.321.7275.1493

[6] Stevens, D.S. and Edwards, W.T. (1999) Management of Pain in Intensive Care Settings. Surgical Clinics of North America, 79, 371-386. https://doi.org/10.1016/S0039-6109(05)70387-X

[7] Cook, T.M. (2000) Combined Spinal-Epidural Techniques. Anaesthesia, 55, 42-64. https://doi.org/10.1046/j.1365-2044.2000.01157.x

[8] Stamenkovic, D. and Karanikolas, M. (2012) Combined Spinal Epidural Anesthesia and Analgesia. Epidural Analgesia-Current Views and Approaches. Croatian: In Tech, 16, 115-134.

[9] Swami, A., Mchale, S., Abbott, P. and Morgan, B. (1993) Low-Dose Spinal-Anesthesia for Cesarean-Section Using Combined Spinal-Epidural (CSE) Technique. Anesthesia and Analgesia, 76, S423-S423.

[10] Rawal, N., Holmström, B., Crowhurst, J.A. and Van Zundert, A. (2000) The Combined Spinal-Epidural Technique. Anesthesiology Clinics of North America, 18, 267-295. https://doi.org/10.1016/S0889-8537(05)70164-4

[11] Fan, S.Z., Susetio, L., Wang, Y.P., Cheng, Y.J. and Liu, C.C. (1994) Low Dose of Intrathecal Hyperbaric Bupivacaine Combined with Epidural Lidocaine for Cesarean Section-A Balance Block Technique. Anesthesia \& Analgesia, 78, 474-477.

https://doi.org/10.1213/00000539-199403000-00009

[12] Hamdani, G.A., Chohan, U. and Zubair, N.A. (2002) Clinical Usefulness of Sequential Combined Spinal Epidural Anaesthesia in High Risk Geriatric Patients for Major Orthopaedic Surgery. Journal of Anaesthesiology, Clinical Pharmacology, 18, 163-166.

[13] Thoren, T., Holmström, B., Rawal, N., Schollin, J., Lindeberg, S. and Skeppner, G. (1994) Sequential Combined Spinal Epidural Block versus Spinal Block for Cesarean Section: Effects on Maternal Hypotension and Neurobehavioral Function of the Newborn. Anesthesia and Analgesia, 78, 1087-1092. https://doi.org/10.1213/00000539-199406000-00009

[14] Wakamatsu, M., Katoh, H., Kondo, U., Yamamoto, T. and Tanaka, S. (1991) Combined Spinal and Epidural Anesthesia for Orthopaedic Surgery in the Elderly. Masui. The Japanese Journal of Anesthesiology, 40, 1766-1769.

[15] Curelaru, I. (1979) Long Duration Subarachnoid Anaesthesia with Continuous Epidural Block. Praktische Anasthesie, Wiederbelebung Und Intensivtherapie, 14, 71.

[16] Bhosale, G. and Shah, V. (2008) Combined Spinal-Epidural Anesthesia for Renal Transplantation. Transplantation Proceedings, 40, 1122-1124. https://doi.org/10.1016/j.transproceed.2008.03.027

[17] Haberal, M., Emiroglu, R., Arslan, G., Apek, E. and Karakayali, H. (2002) Living-Donor Nephrectomy under Combined Spinal-Epidural Anesthesia. Transplantation Proceedings, 34, 2448-2449. https://doi.org/10.1016/S0041-1345(02)03173-1

[18] Urmey, W.F. (2000) Combined Spinal Epidural Anesthesia. Techniques in Regional 
Anesthesia and Pain Management, 4, 13-18. https://doi.org/10.1016/S1084-208X(00)70009-7

[19] Bernstein, R.L. and Rosenberg, A.D. (1993) Manual of Orthopedic Anesthesia and Related Pain Syndromes. Churchill Livingstone, New York.

[20] Tummala, V., Rao, L.N., Vallury, M.K. and Sanapala, A. (2015) A Comparative Study-Efficacy and Safety of Combined Spinal Epidural Anesthesia versus Spinal Anesthesia in High-Risk Geriatric Patients for Surgeries around the Hip Joint. Anesthesia, Essays and Researches, 9, 185-189. https://doi.org/10.4103/0259-1162.153764

[21] Holmström, B., Laugaland, K., Rawal, N. and Hallberg, S. (1993) Combined Spinal Epidural Block versus Spinal and Epidural Block for Orthopaedic Surgery. Canadian Journal of Anaesthesia, 40, 601-606. https://doi.org/10.1007/BF03009695

[22] Kanonidou, Z. and Karystianou, G. (2007) Anesthesia for the Elderly. Hippokratia, 11, 175-177.

[23] Bhattacharya, D., Tewari, I. and Chowdhuri, S. (2007) Comparative Study of Sequential Combined Spinal Epidural Anaesthesia versus Spinal Anaesthesia in High Risk Geriatric Patients for Major Orthopaedic Surgery. Indian Journal of Anaesthesia, 51, 32-36.

[24] Krishnan, S., Madhu, D. and Maya Sandhya, M.S. (2018) Combined Spinal Epidural Block Using Low Dose Intrathecal Bupivacaine with Fentanyl in High Risk Geriatric Patients for Proximal Femoral Surgeries. Journal of Medicine Science and Clinical Research, 6, 32491-32498. https://doi.org/10.18535/jmscr/v6i1.171

[25] Gupta, P., Dua, C., Verma, U., Saxena, K. and Chakraborty, I. (2013) Sequential Combined Spinal Epidural versus Epidural Anaesthesia in Orthopaedic and Gynaecological Surgery: A Comparative Evaluation. Indian Journal of Anaesthesia, 46, 453-456.

[26] Pusapati, R.N., Sivashanmugam, T. and Ravishankar, M. (2010) Respiratory Changes during Spinal Anaesthesia for Gynaecological Laparoscopic Surgery. Journal of Anaesthesiology Clinical Pharmacology, 26, 475-479.

[27] Shintani, N., Ishiyama, T., Shibuya, K., Ichikawa, M., Okawa, I. and Matsukawa, T. (2009) Combined Spinal-Epidural Anesthesia for Abdominal Surgery in A Patient with Chronic Obstructive Pulmonary Disease. Masui. The Japanese Journal of Anesthesiology, 58, 1310-1312.

[28] Mutukwa, T., Gonah, L., Ndhlala, A.R. and Saurombe, D.T. (2017) Is Oxygen Supplementation Necessary for Patients under Spinal Anaesthesia?-A Prospective Hospital-Based Study. Medical Journal of Zambia, 44, 45-51.

[29] Muñoz, H.R., Dagnino, J.A., Rufs, J.A. and Bugedo, G.J. (1992) Benzodiazepine Premedication Causes Hypoxemia during Spinal Anesthesia in Geriatric Patients. Regional Anesthesia \& Pain Medicine, 17, 139-142.

[30] Regli, A., Von Ungern-Sternberg, B.S., Reber, A. and Schneider, M.C. (2006) Impact of Spinal Anaesthesia on Peri-Operative Lung Volumes in Obese and Morbidly Obese Female Patients. Anaesthesia, 61, 215-221. https://doi.org/10.1111/j.1365-2044.2005.04441.x

[31] Trembach, N. and Zabolotskikh, I. (2017) The Influence of Age on Interaction between Breath-Holding Test and Single-Breath Carbon Dioxide Test. BioMed Research International, 2017, Article ID: 1010289. https://doi.org/10.1155/2017/1010289

[32] Whitelaw, W.A., Mcbride, B. and Ford, G.T. (1987) Effect of Lung Volume on 
Breath Holding. Journal of Applied Physiology, 62, 1962-1969.

[33] Bowdle, T.A., Greichen, S.L., Bjurstrom, R.L. and Schoene, R.B. (1987) Butorphanol Improves Co2 Response and Ventilation after Fentanyl Anesthesia. Anesthesia \& Analgesia, 66, 517-522. https://doi.org/10.1213/00000539-198706000-00006

[34] Feiner, J.R., Bickler, P.E. and Severinghaus, J.W. (1995) Hypoxic Ventilatory Response Predicts the Extent of Maximal Breath-Holds in Man. Respiration Physiology, 100, 213-222. https://doi.org/10.1016/0034-5687(94)00132-J

[35] Swarnkar, N., Ghosh, A. and Yadav, A. (2007) Sequential Combined Spinal Epidural Block Superior to Epidural Block for Total Abdominal Hysterectomy in Patient and Surgeons Perspective: Double Blind Randomized Control Trial. The Internet Journal of Anesthesiology, 18, 672-690. https://doi.org/10.5580/129 